\title{
A Case Study: Performance Comparison of Solar Power Generation between GridLAB-D and SAM in Dili Timor Leste
}

\section{Jose Manuel Soares de Araujo}

Electrical and Electronic Engineering Division, Graduate School of Natural Science and Technology, Gifu University, Gifu, Japan

Email: isakhar.inside13@gmail.com

How to cite this paper: de Araujo, J.M.S. (2020) A Case Study: Performance Comparison of Solar Power Generation between GridLAB-D and SAM in Dili Timor Leste. Journal of Power and Energy Engineering, 8, 1-22.

https://doi.org/10.4236/jpee.2020.88001

Received: April 18, 2020

Accepted: July 31, 2020

Published: August 3, 2020

Copyright $\odot 2020$ by author(s) and Scientific Research Publishing Inc. This work is licensed under the Creative Commons Attribution International License (CC BY 4.0).

http://creativecommons.org/licenses/by/4.0/

\begin{abstract}
Study of comparison of solar power generation between the GridLAB-D tool and System Advisor Model (SAM) in Dili, Timor Leste is presented in this paper. Weather Research and Forecasting (WRF) model is used to simulate solar radiation for one calendar year from January to December 2014 using six-hourly interval $1^{\circ} \times 1^{\circ}$ NCEP FNL analysis data. The one calendar year results from the WRF model will be used as input data for GridLAB-D and SAM to estimate the solar power generation. GridLAB-D is an open-source and analysis tool designed to operate the distribution power systems with a high-performance algorithm. System Advisor Model version SAM 2017.9.5 is used to estimate solar power performance with Photovoltaics (PVWatts)Commercial Distributed model. This model is designed to analyze the performance and the financing of renewable energy for electricity generation. The results show the lowest solar radiation is $512 \mathrm{~W} / \mathrm{m}^{2}$ obtained in June with an average monthly power of $20.6 \mathrm{~kW}$ and $30.55 \mathrm{~kW}$ generated from the SAM model and the GridLAB-D simulator, respectively. Meanwhile, the highest solar radiation is $1100 \mathrm{~W} / \mathrm{m}^{2}, 1112 \mathrm{~W} / \mathrm{m}^{2}, 1046 \mathrm{~W} / \mathrm{m}^{2}$, and $1077 \mathrm{~W} / \mathrm{m}^{2}$ obtained in October, November, December, and January with an average monthly power of $55.72 \mathrm{~kW}, 62.44 \mathrm{~kW}, 56.65 \mathrm{~kW}$, and $56.97 \mathrm{~kW}$ from the SAM model, in the other hand, $48.89 \mathrm{~kW}, 51.31 \mathrm{~kW}, 55.51 \mathrm{~kW}$, and $57.18 \mathrm{~kW}$ generated by the GridLAB-D. Finally, the results show that the performance of the GridLAB-D and the SAM model was quite good because both model precisely presented values are almost closest to each other. This study proposes that the results of solar output power from both methods, GridLAB-D and SAM can be used to design grid-connected or stand-alone electric power projects to increase the quality of electricity generation in Dili, Timor Leste.
\end{abstract}


Keywords

GridLAB-D, System Advisor Model, Solar Power Generation, Timor Leste, WRF

\section{Introduction}

According to the strategic plan for the development of Timor Leste from the year, 2011 to 2030, renewable energy such as solar-, wind-, and hydro power, including biomass and any other source, has become one of the main targets to supply the electricity [1]. An investment in the new power plant with the upgrade of distribution and transmission systems will be expected to supply the electricity with high quality and its performance. The development of the renewable energy system will reduce and improve the conditions of living for the populations in remote areas or isolate areas which unable to access the electricity. The feasibility study of renewable energy system about the output power generation which conducted in this study will be expected using as references for the development of Timor Leste in the future regarding the planning of construction for the renewable energy system based on the number populations and an analyzing of output energy for the long term period. Meanwhile, implementing solar power as one part of the renewable system will be expected also to drive the growth of the economy in rural areas. Therefore, the forecasting of solar radiation is the most important factor to analyze the output power generation of the solar power plant. Hourly or daily forecasting is very helpful for optimization at different forecast horizons and its diffuse and direct components are important for the operation of the solar power system. Timor Leste is a tropical country with available good solar radiation almost all the years suitable for implementing solar energy. Figure 1 shows the plotting of solar radiation analysis data in the Timor Leste region on the date of March 23 of 2014 at 10 AM local standard time (LST), where this day was sunny. The plotting is showing that solar radiation obtained above $1000 \mathrm{~W} / \mathrm{m}^{2}$ indicating a high possibility for solar farm installation with a high output of solar power.

To forecast hourly or daily solar radiation over an interest region, the forecasting of the presence of clouds needs to be clarified under all-sky conditions. However, hourly or daily solar radiation is not available in many cases as it is observed at a very limited number of weather stations and due to the cost of maintaining the observation equipment in an undergoing-developing country. Developing methods of study for estimation of solar radiation has been paid attention in locations which no observed values are available. These methods are efficient and simple for weather forecasting. The use of Numerical Weather Prediction (NWP) and time series methods are particularly promising for approaching the variation of solar radiation modeling. These methods are applied the different weather variables to make changes in solar radiation. Meanwhile, it 


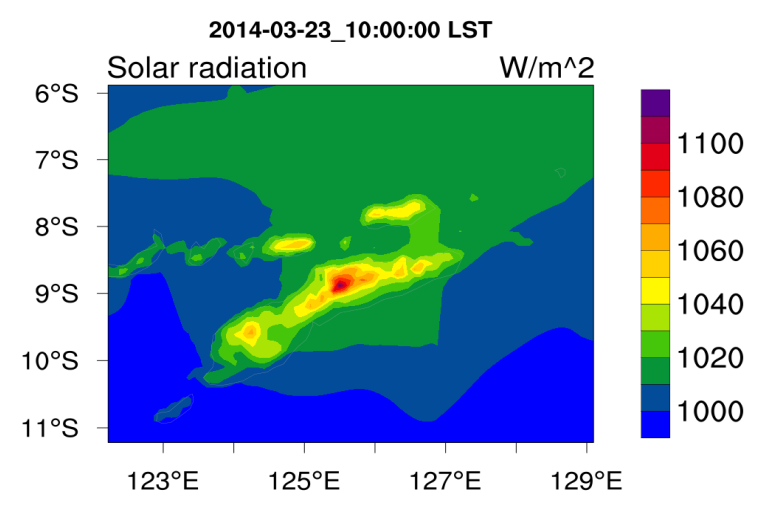

Figure 1. Plotting of analyses of solar radiation in Timor Leste.

is also very important to understand the characteristic of solar radiation in the implementation in integration and operation in current power grids, and in the planning of energy management since the forecasting of photovoltaic (PV) power generation is dependent on the climate. The output values from an NWP have been considered useful data in forecasting the power generation of the PV system.

Nowadays, many developing countries have been applying renewable systems such as solar and wind energy to supply electricity in all territory [2]. Particularly, countries that geographically located close to the equator line are the most which have a great amount of sunlight all year, but a shortage of wind and water in some areas. For all these reasons, the implementation of solar energy in Timor Leste is an excellent choice to supply electricity for consumers since Timor Leste is a tropical country located around the equator. In addition, increasing population and energy demand in the undergoing developing countries brought many concerns such as environmental problems, pollution, poverty, and health problems. Solar energy is the best choice to provide excellent energy to reduce greenhouse gas (GHG) emissions and air pollutants especially in remote rural areas in which the grid connections are technically not available.

Many researchers have conducted a study regarding renewable energy such as wind and solar energy. Jose Manuel Soares de Araujo [3] conducted a study of wind speed and wind power generation above mountain area with a height of 100 and 120 meters above ground level for location in Dili Timor Leste in 2014 using the WRF model and SAM. He showed that strong wind speed for some months reaching $\pm 14 \mathrm{~m} / \mathrm{s}$ to generate high wind power. His study proposed that applying the installation and construction of a wind energy system in Dili around the Hera mountain area as an additional-energy-generator will be one solution to deal with energy demand in Dili, Timor Leste. A. Dobos et al. [4] introduced System Advisor Model (SAM) for calculating the performance of the solar thermal concentrating system for six CSP model systems such as empirical through model, physical through model, generic solar model, molten salt power tower, direct steam power tower, and dish Stirling. Their study showed a very low root mean square deviations and provided a significant reduction in computational 
time for the same model. Torsten et al. [5] conducted a study of a modeling framework for wind power integration systems where loads become an additional resource. The modeling framework conducted on the Olympic Peninsula, Washington, USA to represent a physical demonstration project. The results indicate that the Demand Response (DR) implementation is used to assist the integration of renewable energy resource to ensure the functionality of the overall system. Emeka et al. [6] used SAM to characterize the performance of the power plant and aid the analysis and evaluation of the power plant performance. They focused on the modeling and simulation of a $50 \mathrm{~kW}$ concentrated solar power (CSP) located in Crowley, Lousiana. Their model was validated with the actual power plant data for comparison purposes and showed a good correlation between the predict results and the actual power plant data.

This study is continuously from the previous study regarding wind speed simulation and wind power estimation in Dili, Timor Leste [3]. The objective of this paper is to compare the output power of solar PV panels between the System Advisor Model (SAM) and the GridLAB-D tool for location in Dili-Timor Leste. Results from Weather Research and Forecasting (WRF) nesting model simulation for one calendar year are used as input data by the GridLAB-D and SAM to generate the solar output power for comparison purposes. The input data for both methods is provided by WRF mesoscale model using six-hourly interval $1^{\circ} \times 1^{\circ}$ NCEP FNL analysis data used as Global Forecast System (GFS) obtained freely from the NCEP FNL website. The values of input data such as temperature, relative humidity $(\mathrm{RH})$, wind speed, solar direct and solar diffuse are used to simulate solar energy by both methods, GridLAB-D and SAM, respectively.

This paper is organized as follows. The study area and the observation data are described in Section 2. Section 3 describes the description of the methods which are used in this study; in particular, it presents the configuration of the WRF model, SAM, GridLAB-D, and four evaluation error metrics. The results are presented in Section 4; the performance of comparison between observed and simulated data, plotting of solar radiation in two seasons, output values of the PV system, annual energy production, after-tax cash flow, and comparison of solar output power between GridLAB-D and SAM are presented in this section. Finally, section 5 describes a summary of the results and conclusions.

\section{Study Area and Observation Data}

Simulation of solar radiation was conducted in Hera town [7] (latitude: $8^{\circ} 33^{\prime} 03.9^{\prime \prime} \mathrm{S}$, longitude: $125^{\circ} 39^{\prime} 33.7^{\prime \prime E}$ ) which is located $12.4 \mathrm{~km}$ east of Dili. Figure 2(a) shows plotting of study area and Figure 2(b) is location of weather station at Hera campus. Hera town is a crop area mixed with planting surrounded by the sea in the North side and mountains area in the South side. Based on the simulation data in the year 2014, this area recorded the highest solar radiation of 1113 $\mathrm{W} / \mathrm{m}^{2}$ in October and the lowest solar radiation of $10 \mathrm{~W} / \mathrm{m}^{2}$ in January. Meanwhile, the temperatures of range $32^{\circ} \mathrm{C}$ to $35^{\circ} \mathrm{C}$ are highest observed in October, 
January, February, November and December and the lowest temperatures of range $17^{\circ} \mathrm{C}$ to $20^{\circ} \mathrm{C}$ observed in June and July. This area with hot weather all year was chosen for it has a weather station for comparison purposes with the simulation data. In addition, this area was chosen as it is one of the locations with the high potency of solar radiation for the generation of solar PV power. Meanwhile, results of simulation data will be used as input data to estimate solar output power from two different methods, GridLAB-D and SAM, respectively. This study proposes to analyze the results of electricity generation from the PV system for a long-term period which can be used as grid-connected or stand-alone electric power projects to stabilize energy demand in Dili. This study used Intel(R) Core(TM) i7-7700 CPU @ $3.60 \mathrm{GHz}$ computer, 8 GB of RAM on Linux Ubuntu 16.04 LTS 64 bit operating system. Temperature with 5 minutes interval output from WXT530 Vaisala in Hera will be used to validate with the temperature at $2 \mathrm{~m}$ height from WRF simulation from 21 March to 25 March 2014. In addition, the 120 hours of solar radiation from $1^{\text {st }}$ to $5^{\text {th }}$ June 2015 from same weather station were used to validate in order to analyze the performance of the WRF model.

\section{Methodology}

\subsection{Description of the WRF Model}

Weather Research and Forecasting (WRF) [8] version 3.9.1 was used in this study. The performance of WRF model configuration such as nesting level, spacing and resolution of the grid, geographical shift and time resolution has been implemented in the centers of the domain. Skamarock et al., 2008 suggested coarsest grid distance magnitude (in kilometers) should be divided by 3 to stabilize the WRF model computational to keep a ratio of $1 / 3$. Horizontal nesting resolution is allowed in the WRF model to introduce finer grid simulation over a region. Meanwhile, one-way and two-way grid nesting technique including initial and lateral boundary conditions are supported by this model to interact with a parent domain and a coarse with input from higher resolution. To increase simulation speed with efficient and accurate, the inner grid domain of this model must be small. These simulations were done based on the NCEP FNL Operational Model Trophospheric website (https://rda.ucar.edu/datasets/ds083.2/). The spatial resolution was six-hourly intervals $1 \times 1$ with 00 UTC, 06 UTC, 12 UTC, and 18 UTC datasets.

Table 1 is the configuration of the WRF nesting domain. Figure 3(a) shows three two-way-nested domain from west to east and south to north with grid resolution 9-, 3-, and $1 \mathrm{~km}$ and grid size of parent domain are $86 \times 68(\mathrm{~d} 01), 88 \times$ 88 as 1 st nested domain(d02), and $100 \times 100$ as the innermost domain (d03). Figure $3(b)$ is the view of terrain height of domain d03. This simulation used Single-Moment 5-class (WSM5) [9] scheme for microphysics which performs well forecasting over a region and considers the cloud parameters such as cloud water, cloud ice, rain, and snow to exist and melting of snow. The general circulation model (GCM) for the Rapid Radiative Transfer Model (RRTMG) was used for shortwave (SW) and longwave (LW) radiation [10] [11]. RRTMG is a new 


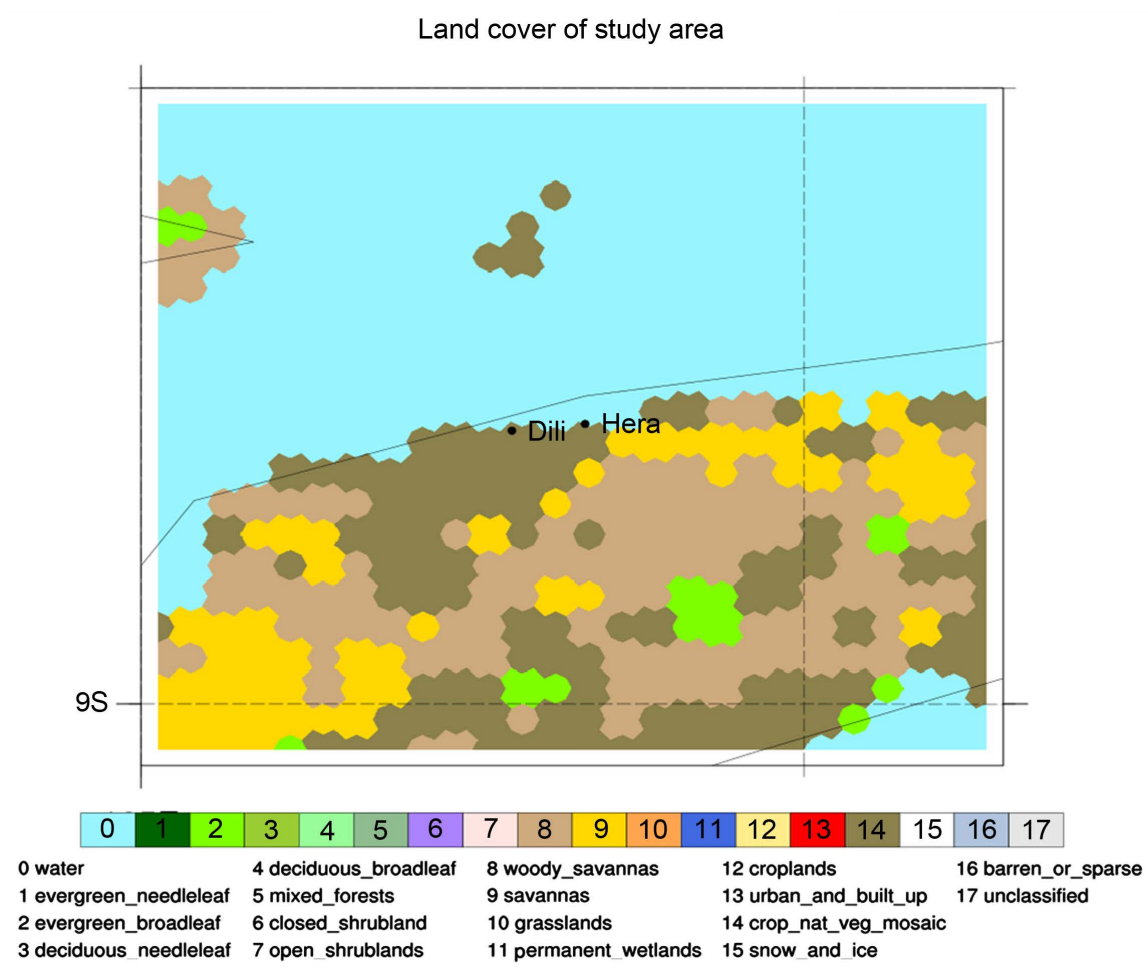

(a)

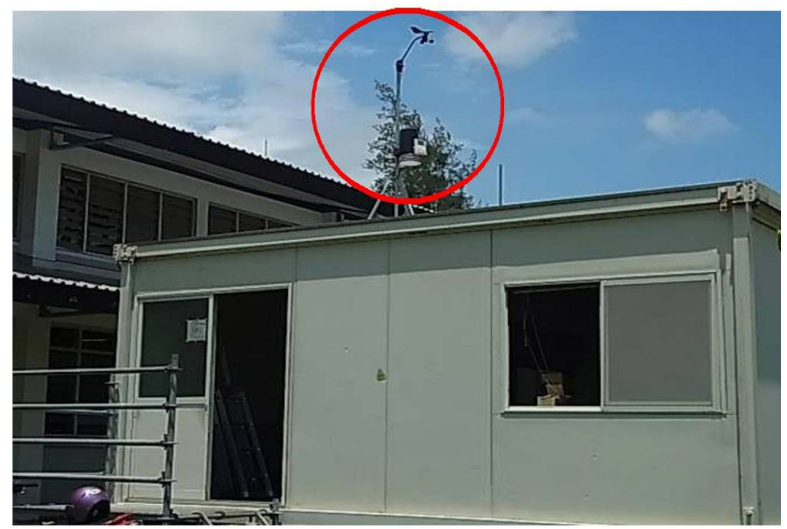

(b)

Figure 2. (a) Land cover of study area; (b) Location of Hera campus weather station (lat: $8^{\circ} 33^{\prime} 03.9^{\prime \prime}$, long: $125^{\circ} 39^{\prime} 33.7^{\prime \prime}$ ) (see [3]).

modification scheme from the RRTM scheme to improve the computational efficiency, to update the formatting code, and to represent the variability of the cloud. Noah Land Surface Model was used for the land surface [12]. Noah LSM is a collaborative effort input data such as NCEP, NCAR, and AFWA to evaluate the performance impact of the land surface on WRF model simulation. Yonsei University scheme was used for the planetary boundary layer [13]. This PBL scheme is to express the vertical gradient and the turbulent fluxes of the variable. Monin-Obukhov MM5 similarity theory was used for the surface layer [14]. This theory used the framework to compute the surface turbulent fluxes. Because of parent grid sizes are not greater than $9 \mathrm{~km}$, theoretically, the cumulus 
Table 1. Computational conditional used in WRF simulation (see ref. 3).

\begin{tabular}{|c|c|}
\hline Period & $\begin{array}{l}\text { Start: } 1 \text { January } 2014 \\
\text { End: } 31 \text { December } 2014\end{array}$ \\
\hline Input data & NCEP FNL (6-hourly, $1^{\circ} \times 1^{\circ}$ ) \\
\hline Nesting & Two-way nesting \\
\hline Domain & $\begin{array}{l}\text { Domain } 1 \text {, d01 }(9 \mathrm{~km}, 86 \times 68 \text { grids }) \\
\text { Domain } 2 \text {, d02 }(3 \mathrm{~km}, 88 \times 88 \text { grids }) \\
\text { Domain } 3 \text {, d03 }(1 \mathrm{~km}, 100 \times 100 \text { grids })\end{array}$ \\
\hline Map projection & Mercator \\
\hline Vertical layer & 38 \\
\hline Geographic data resolution & $10 \mathrm{~m}, 5 \mathrm{~m}, 2 \mathrm{~m}$ \\
\hline Microphysics & WRF Single-Moment 5-class scheme \\
\hline Longwave radiation & RRTMG scheme \\
\hline Shortwave radiation & RRTMG scheme \\
\hline Surface layer & MM5 scheme \\
\hline Land surface & Noah land surface model \\
\hline Planetary boundary layer & Yonsei University scheme \\
\hline Cumulus parameterization & None \\
\hline
\end{tabular}

parameterization must be turned off. NCL (NCAR Command Language) programming language version 6.5.0 was used to plot the forecast of solar radiation and its grid point. NCL is used to analyze scientific data: climate data, oceanography data, and meteorological data [15].

\subsection{Description of the GridLAB-D}

GridLAB-D [16] is developed and maintained at Pacific Northwest National Laboratory (PNNL) in Richland Washington in the U.S. Department of Energy (DOE) government research laboratory as part of the GridWise program. It is an open-source and analysis simulator tool that provides information on how to use the utilities to take advantage of the latest energy technologies. This tool has advanced modeling techniques that provide high valuable information to users who want to design and operate the distribution systems including how to use the utilities with a high-performance algorithm to deliver energy in end-use modeling. It is flexible and can be integrated with any variety of third-party data management. This simulator tool can be used to simulate energy from the generation until the end-user and simulate many households in a village or city. It is also very useful to simulate renewable energy systems such as solar and wind energy. The more advantages of using a GridLAB-D tool such as: 1) GridLAB-D can be used to run time-series solutions. 2) Implementing a simulation method in the end-user model and including appliances, equipment model and consumer model. 3) Retail modeling tool including the model of SCADA tool, the technology of metering and business and operation for the simulation. 4) Creating 


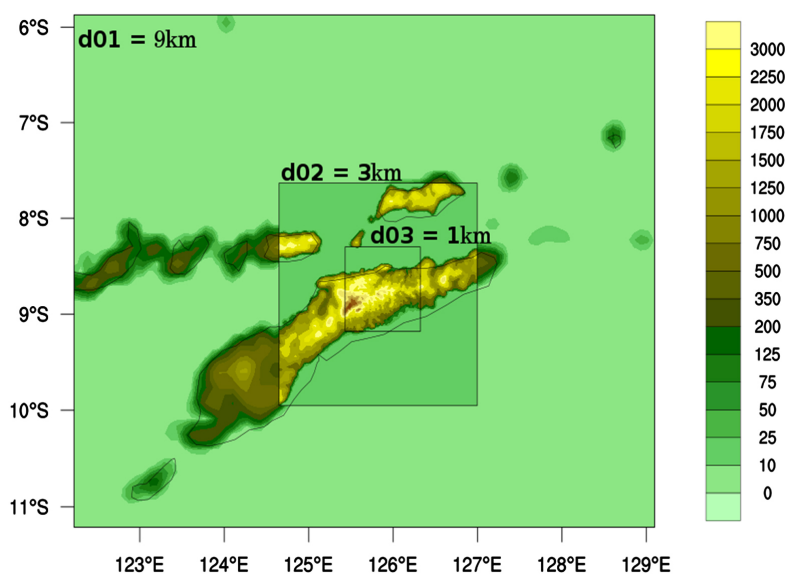

(a)

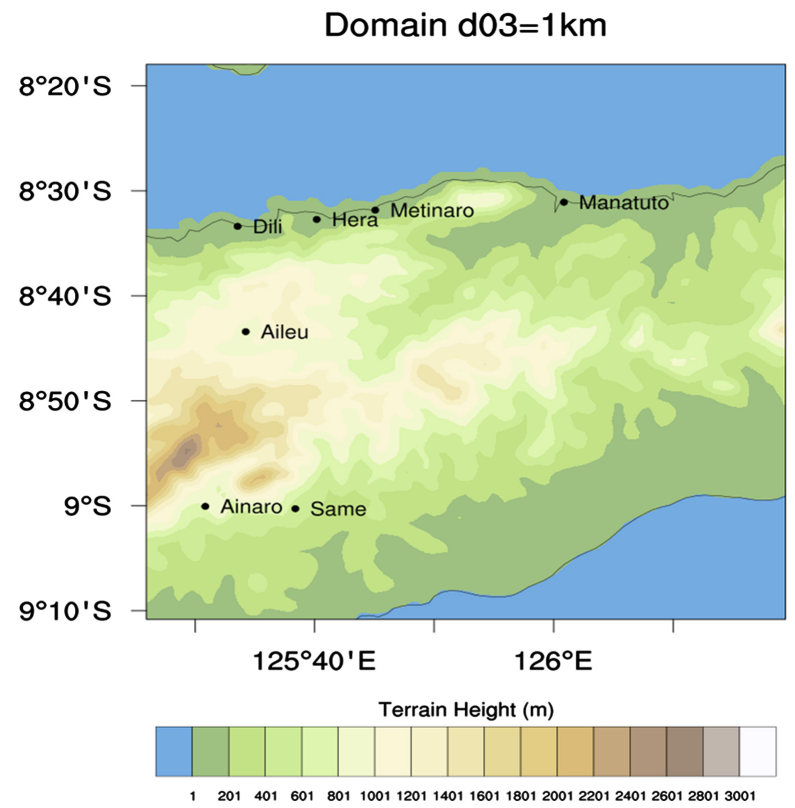

(b)

Figure 3. (a) The configuration of three two-way-nested domain; (b) View of terrain height of domain d03 $(1 \mathrm{~km})$. Data of domain d03 $(1 \mathrm{~km})$ were used for validation in this study (see [3]).

external links to all text-based tools. 5) It can run efficiently on multiprocessor and multi-core machines.

The 8760 hours of one calendar year data in 2014 from WRF model simulation in Dili, Timor Leste were used to simulate solar power. There were 5 modules used in this simulation such as module tape, module generators, module power flow, module residential and module climate. Module climate uses two objects such as object csv_reader and objects climate to read the input data file in CSV file type. Object meter as part of module generator applies a nominal voltage of $220 \mathrm{~V}$. For generator case, phase CN with panel type of Multi Crystal Silicon is applied with ONLINE generator status. Generator mode of supply-driven applied in an area of $75 \mathrm{~m}^{\wedge} 2$ with 30 degrees of tilt angle, 180 degrees of solar 
azimuth, and the efficiency is 0.14 . This module orientated in Fixed Axis with solar power model was set as default. The inverter object also used phase $\mathrm{CN}$ with ONLINE generator status applied with Constant PQ as the generator mode. The inverter type used Four Quadrant with 0.9 of power factor, the rated power was $150 \mathrm{VA}$, solt tilt model is solpos, and the efficiency inverter was $0.96 \%$. Table 2 shows an example of 24 hours of one calendar year input data from WRF simulation which is used to run the solar power simulation in GridLAB-D simulator. Some variables such as temperature use degree Farad (DegF), solar direct and solar diffuse use $\mathrm{Watt} / \mathrm{square}$ feet $\left(\mathrm{W} / \mathrm{f}^{2}\right)$ as the units.

Table 2. Input data for solar power simulation in GridLAB-D.

\begin{tabular}{|c|c|c|c|c|c|}
\hline \multicolumn{6}{|c|}{ \$state_name $=$ Timor Leste } \\
\hline \multicolumn{6}{|c|}{ \$city_name = Dili } \\
\hline \multicolumn{6}{|c|}{ \$lat_deg $=-8$} \\
\hline \multicolumn{6}{|c|}{ \$lat_min $=-8$} \\
\hline \multicolumn{6}{|c|}{ \$long_deg $=125$} \\
\hline \multicolumn{6}{|c|}{ \$long_min $=125$} \\
\hline \multicolumn{6}{|c|}{ \$timezone_offset $=+9$} \\
\hline & temperature & humidity & wind_speed & solar_dir & solar_diff \\
\hline 2014-01-01 00:00:00 & 78 & 68 & 2.05 & 0 & 0 \\
\hline 2014-01-01 01:00:00 & 78 & 68 & 1.96 & 0 & 0 \\
\hline 2014-01-01 02:00:00 & 78 & 67 & 2.18 & 0 & 0 \\
\hline 2014-01-01 03:00:00 & 78 & 67 & 2.3 & 0 & 0 \\
\hline 2014-01-01 04:00:00 & 78 & 66 & 2.34 & 0 & 0 \\
\hline 2014-01-01 05:00:00 & 77 & 65 & 2.25 & 0 & 0 \\
\hline 2014-01-01 06:00:00 & 77 & 66 & 2.34 & 0 & 0 \\
\hline 2014-01-01 07:00:00 & 81 & 67 & 2.29 & 24.89 & 5.94 \\
\hline 2014-01-01 08:00:00 & 83 & 66 & 2.08 & 65.40 & 7.43 \\
\hline 2014-01-01 09:00:00 & 85 & 64 & 1.93 & 73.95 & 10.68 \\
\hline 2014-01-01 10:00:00 & 86 & 64 & 2.18 & 83.51 & 10.12 \\
\hline 2014-01-01 11:00:00 & 88 & 66 & 2.65 & 83.89 & 12.63 \\
\hline 2014-01-01 12:00:00 & 88 & 67 & 3.85 & 94.01 & 5.94 \\
\hline 2014-01-01 13:00:00 & 88 & 67 & 4.22 & 85.65 & 13.47 \\
\hline 2014-01-01 14:00:00 & 88 & 70 & 4.65 & 92.64 & 6.50 \\
\hline 2014-01-01 15:00:00 & 88 & 74 & 4.06 & 85.74 & 9.38 \\
\hline 2014-01-01 16:00:00 & 87 & 76 & 3.79 & 87.32 & 5.20 \\
\hline 2014-01-01 17:00:00 & 86 & 78 & 3.07 & 74.13 & 6.59 \\
\hline 2014-01-01 18:00:00 & 84 & 83 & 2.81 & 44.40 & 6.50 \\
\hline 2014-01-01 19:00:00 & 81 & 87 & 1.1 & 0 & 0 \\
\hline 2014-01-01 20:00:00 & 80 & 89 & 1.07 & 0 & 0 \\
\hline 2014-01-01 21:00:00 & 81 & 94 & 1.89 & 0 & 0 \\
\hline 2014-01-01 22:00:00 & 77 & 90 & 1.08 & 0 & 0 \\
\hline 2014-01-01 23:00:00 & 78 & 82 & 2.16 & 0 & 0 \\
\hline
\end{tabular}




\subsection{Description of the SAM}

System Advisor Model version SAM 2017.9.5 [17] was used in this study to predict and estimate the renewable energy technologies. SAM was first developed in 2006 by the National Renewable Energy Laboratory (NREL) in partnership with the US Department of Energy (DOE) Solar Energy Technologies Program and conjunction with Sandia National Laboratories, the University of Wisconsin aims to help the researchers to simulate the financing and performance of renewable energy. This model can be used to design grid-connected or stand-alone electric power projects for electricity generation such as PV system, wind system, geothermal systems, thermal power plant model, and biomass. In this study, the Photovoltaics (PVWatts) - Commercial Distributed model of the SAM was used to simulate solar power generation. An hourly performance data is used in this model to calculate and estimate the annual electricity including interest rates, incentives, and system specifications. SAM then reports all results in tables and graphs to analyze its performance. A weather file with 8760 hourly from the WRF model simulation was used to simulate and estimate the electricity load and financing from the PV system. To remain the input variables for the solar farm construction, the tilt, and azimuth angle, the total installed costs inverter size, system nameplate size, array type, module type, DC to AC ratio, and inverter efficiency are default value as the starting point for the solar farm project. The total installed costs, analysis period, degradation rate, debt percent are used for analyzing the financing of the models. In this study, the LCOE options are selected to estimate the output of the financial. The values of financial parameters such as state income tax rate, federal income tax rate, and insurance rate annual are used based on the reports from the Ministry of Finance policies in Timor Leste [18]. In addition, Timor Leste uses the US dollar as the current currency for daily life and marketing which is means the implementation of the finance in the SAM can be well extrapolated in this region. Sales tax, depreciation, electricity rates, and salvage value were all set with values specified in the SAM. Table 3 shows the configuration of characteristics from the PV panel system used in this study.

Evaluation cost of energy for Levelized Costs of Energy (LCOE) [19] from the PV system was presented in this study. LCOE metric is the most used to express the capital cost of operation and maintenance of the PV system. The install capital cost, the annual operating expenditures, the discount rate, the operational life, and the net annual energy production are the five important parameters in the LCOE metric. The LCOE metric can be expressed in Equation (1):

$$
\mathrm{LCOE}=\frac{\mathrm{FCR} \times \mathrm{ICC}+\mathrm{AOE}}{\mathrm{AEP}_{\text {net }}}
$$

where: $\mathrm{LCOE}=$ levelized cost of energy $(\$ / \mathrm{MWh})$

$$
\begin{aligned}
& \mathrm{FCR}=\text { fixed charge rate }(\%) \\
& \mathrm{ICC}=\text { installed capital cost }(\$) \\
& \mathrm{AOE}=\text { annual operating expenses }(\$ / \text { year }) \\
& \mathrm{AEP}_{\text {net }}=\text { net annual energy production }(\mathrm{MWh} / \text { year) }
\end{aligned}
$$


Table 3. More characteristic of solar PV system.

\begin{tabular}{cc}
\hline System name plate size & 250 \\
Module type & Standard \\
DC to AC ratio & 1 \\
Rate inverter size & $250 \mathrm{kWac}$ \\
Inverter efficiency & $96 \%$ \\
Array type & Fixed open rack \\
Tilt & 30 degrees \\
Azimuth & 180 degress \\
Analyses period & 25 years \\
Total installed cost & $\$ 53,183,375$ \\
Degradation rate & $0.5 \% /$ year \\
Debt percent & $0 \%$ \\
State income tax rate & $10 \%$ \\
Federal income tax rate & 0 \\
Insurance rate annual & $0.5 \%$ \\
\hline
\end{tabular}

\subsection{Error Metrics}

Two of three widely following Diagne et al. [20] were used to evaluate accuracy between simulated data and observed data such as root mean square (RMSE) and the mean bias error (MBE), and expressed in $\mathrm{W} / \mathrm{m}^{2}$. Meanwhile, solar radiation is normalized in the considered period for error percentage using the normalized RMSE (nRMSE) and the normalized MBE (nMBE) and expressed in \% [21] [22]. These error metrics are defined as below;

$$
\begin{gathered}
\mathrm{MBE}=\frac{1}{n} \cdot \sum_{i=1}^{n}\left(\text { pred }_{i}-\text { obs }_{i}\right) \\
\mathrm{RMSE}=\sqrt{\frac{1}{n} \cdot \sum_{i=1}^{n}\left(\text { pred }_{i}-o b s_{i}\right)^{2}} \\
\mathrm{nRMSE}=\left[\frac{\mathrm{RMSE}}{\text { Rmax }^{\prime} \text { Rmin }}\right] * 100 \\
\mathrm{nMBE}=\left[\frac{\mathrm{MBE}}{\text { Rmax }- \text { Rmin }}\right] * 100
\end{gathered}
$$

where $n$ is the total number of points to compare (in which both the observed and simulated values exist), pred represented WRF simulated data from domain d03 and obs represented weather station observed data, Rmax is the maximum value of temperature and solar radiation and $R \min$ is the minimum value of temperature and solar radiation. Respectively, these two metrics are especially for measuring the dispersion of model (RMSE) and average bias (MBE) and an accuracy percentage error calculation: nRMSE and nMBE.

\section{Results}

This section presented the results of the performance comparison between ob- 
served and simulated data, plotting of solar radiation in two seasons, output values of the PV system, annual energy production, after-tax cash flow, and comparison of solar output power between GridLAB-D and SAM. Figure 4(a) shows the plotting of temperature comparison between the WRF model and weather station data. Forecasting of decreasing, increasing, and unstable temperature is affected by decreasing and increasing relative humidity (RH) and wind speed. The performance of 5 days comparison results of temperature from 21st to 25th March 2014 was quite good. The temperature at $2 \mathrm{~m}$ of WRF simulated data showed $\pm 3^{\circ} \mathrm{C}$ lower compared to weather station observed data in the daytime and $\pm 2{ }^{\circ} \mathrm{C}$ different in the night time. In this present study, the relative humidity data for five days obtaining from time and date homepage [23] for location in Dili Timor Leste were used to analyze the difference between simulate and observed data. However, the temperature at $2 \mathrm{~m}$ of WRF simulation was slightly different from the weather station observed data in the midday time and night time may be caused by:

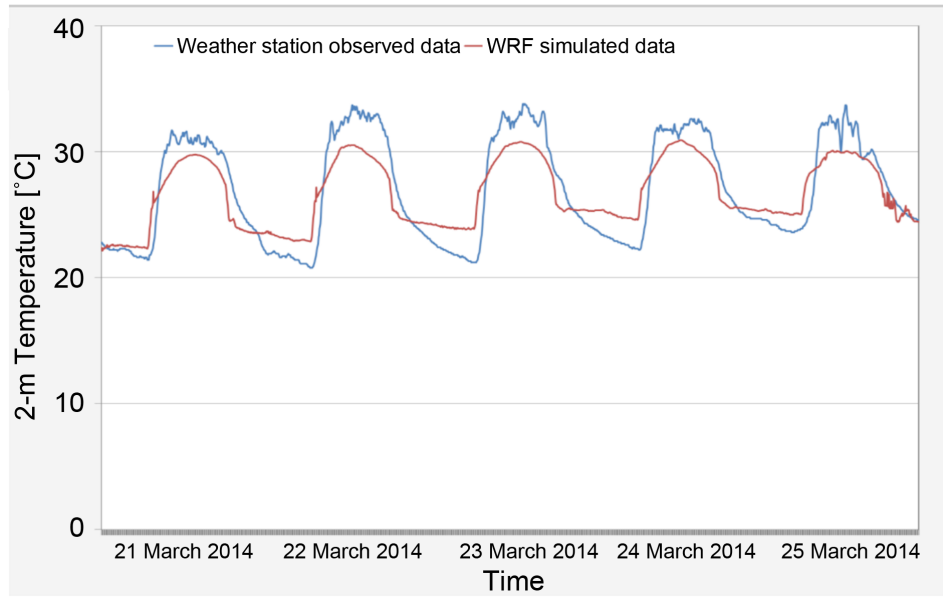

(a)

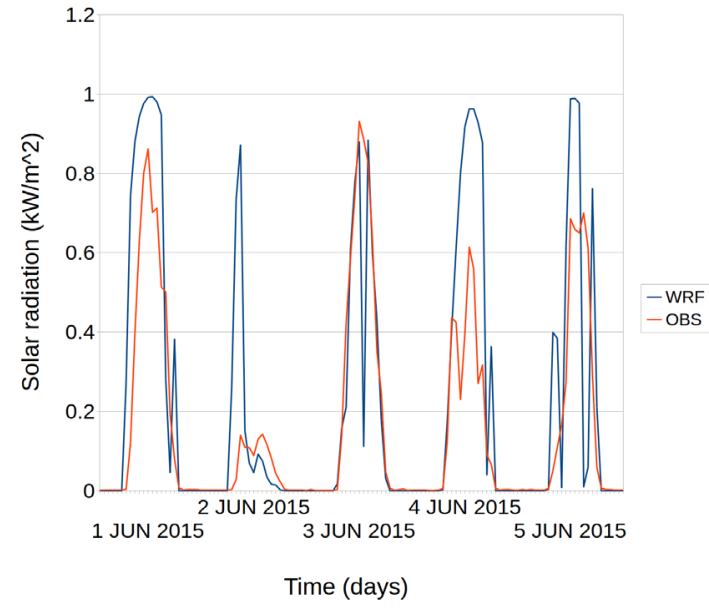

(b)

Figure 4. (a) Comparison of temperature at $2 \mathrm{~m}$ between observed and simulated data; (b) Comparison of solar radiation between observed and simulated data. 
1) The relative humidity $(\mathrm{RH})$ from the observed data obtaining from the date and time homepage showed the $\mathrm{RH}$ during the night time was obtained about $21 \%-34 \%$ higher compared to the RH generated by the WRF simulation as it may affect the temperature of observed data higher than simulated data during night time.

2) The RH will only affect temperature become unstable when the pressure reaching more than $1005 \mathrm{hPa}$ for local climate environments. The observed data from the date and time homepage showed that the values of the pressure reached from 1006 to $1011 \mathrm{hPa}$ higher than 999 to $1002 \mathrm{hPa}$ from the WRF simulation. This study assumed that the high values of pressure from the observed may affect the unstable temperature of the observed data during the daytime.

Figure 4(b) shows the plotting of solar radiation comparison between the WRF model and weather station data. A total of 120 hours of direct normal irradiance (DNI), diffuse irradiance (DIF), and cos zenith are the three parameters used to estimate solar radiation for the ground calculation by the WRF model. solar radiation can change rapidly due to the presence of the cloud. In this present study, a small cloud was observed about $10 \mathrm{~kg} / \mathrm{m}^{3}$ at noon time on the 1st of June, while on the 2nd, 3rd, and 5th of June, large amount of clouds from $10 \mathrm{~kg} / \mathrm{m}^{3}$ to $1000 \mathrm{~kg} / \mathrm{m}^{3}$ were observed in the midday and continue to night time. All of these presented clouds made variation in forecasting of solar radiation. Table 4 shows the results of the MBE, RMSE, nRMSE, and nMBE error between the simulated and observed data. Results of Table 4 show all metrics of 2-m temperature are positive values indicating a tendency of the estimate of the variable. The results of the error calculation between the WRF model and one meteorological station observed data for five days of solar radiation from 1st to 5th June 2015 and five days of temperature at $2 \mathrm{~m}$ from 21st March to 25th March 2014 are also presented in this work. The four error metrics of RMSE, MBE, nRMSE, and nMBE of 120 hours predictions between the WRF model and the observed data are shown in Table 4. The performance of lower values of RMSE and nRMSE will indicate the accurate prediction of the WRF model. The RMSE and nRMSE will be used to measure the agreement between simulated data (WRF) and observed data (weather station). In this case, the WRF model performed $233.8 \mathrm{~W} / \mathrm{m}^{2}$ for the RMSE error metric and $23.5 \%$ of nRMSE is observed for this prediction. However, the MBE and normalized MBE performed 65.4 $\mathrm{W} / \mathrm{m}^{2}$ and $6.5 \%$ lower compared to the RMSE and nRMSE. On the other hand, the temperature at $2 \mathrm{~m}$ performed also lower error about 1.91 deg.C and $14.7 \%$ for RMSE and nRMSE. However, the MBE and nMBE of temperature at $2 \mathrm{~m}$ show an underestimation of the WRF model as it shows the negative values of

Table 4. RMSE, MBE, nRMSE, and nMBE of the simulated and observed data.

\begin{tabular}{ccccc}
\hline Variable & RMSE & MBE & nRMSE & nMBE \\
\hline 2-m temperature & $1.91^{\circ} \mathrm{C}$ & $-0.33^{\circ} \mathrm{C}$ & $14.7 \%$ & $-2.6 \%$ \\
Solar radiation & $233.8 \mathrm{~W} / \mathrm{m}^{2}$ & $65.4 \mathrm{~W} / \mathrm{m}^{2}$ & $23.5 \%$ & $6.5 \%$ \\
\hline
\end{tabular}


MBE and nMBE, -0.33 deg.C and $-2.6 \%$, respectively. This study also presented the results of solar irradiance on a sunny day and a rainy day. Figure 5(a) and Figure 5(b) show irradiance on a sunny day at 09:00 AM and 3:00 PM time. Meanwhile, Figure 5(c) and Figure 5(d) show irradiance on a rainy day at 09:00 in the morning time and 3:00 p.m. time. The plotting of these two seasons shows the maximum values of the solar radiation reach to $1000 \mathrm{~W} / \mathrm{m}^{2}$.

In this present study, the maximum solar radiation around the Dili area for some months in 2014 reaching $1000 \mathrm{~W} / \mathrm{m}^{2}$ where it can be categorized into one of the strong solar radiation. Figure 6(a). shows hourly solar irradiance generation from the WRF model for one calendar year in 2014. The low solar radiation observed in May, June, and July which have solar radiation less than $1000 \mathrm{~W} / \mathrm{m}^{2}$. However, the lowest solar radiation was $512 \mathrm{~W} / \mathrm{m}^{2}$ observed in June. Meanwhile, the high solar radiation observed in January, February, March, April, August, September, October, November, and December, where the highest solar radiation reached $1100 \mathrm{~W} / \mathrm{m}^{2}, 1112 \mathrm{~W} / \mathrm{m}^{2}, 1046 \mathrm{~W} / \mathrm{m}^{2}, 1077 \mathrm{~W} / \mathrm{m}^{2}$ observed in October, November, December, and January 2014. Since there is the difference in the amount of solar radiation reaches out to the location cause the differences in the amount of electricity generated by the installation of PV system each month. Several studies show daily solar radiation is always affected or influenced by the presence of clouds, temperature, relative humidity, and dust on top of the PV panel for a location.

The results of the comparison between GridLAB-D and SAM performances shows some interesting features. Figure 6(b). shows the comparison of solar output power from the PV system for a period from January to December in 2014. Respectively, the blue curves represent SAM and the red color represents GridLAB-D. The minimum average solar power was observed in May, June and July generated the average solar power $25.21 \mathrm{~kW}, 20.6 \mathrm{~kW}$, and $23.77 \mathrm{~kW}$ from the SAM model. Meanwhile, the maximum average solar power were observed in January, February, March, April, August, September, October, November, and December respectively generated $56.97 \mathrm{~kW}, 50.66 \mathrm{~kW}, 46.87 \mathrm{~kW}, 35.5 \mathrm{~kW}$, $32.83 \mathrm{~kW}, 45.06 \mathrm{~kW}, 55.72 \mathrm{~kW}, 62.44 \mathrm{~kW}$, and $56.65 \mathrm{~kW}$ electricity from the SAM model to the grid. On the other hand, the minimum average solar power was observed in June generated $30.55 \mathrm{~kW}$ of electricity from the GridLAB-D simulator. Meanwhile, the maximum average solar power were observed in January, February, March, April, May, July, August, September, October, November, and December respectively generated $57.18 \mathrm{~kW}, 46.55 \mathrm{~kW}, 40.22 \mathrm{~kW}, 40.84 \mathrm{~kW}$, $38.8 \mathrm{~kW}, 36.67 \mathrm{~kW}, 35.57 \mathrm{~kW}, 44.51 \mathrm{~kW}, 48.89 \mathrm{~kW}, 51.31 \mathrm{~kW}$, and $55.51 \mathrm{~kW}$ electricity from the GridLAB-D to the grid. The graph showed that SAM generated less output power compared to GridLAB-D in April, May, June, July, and August where in these months, the difference up to $15 \%$ to $25 \%$. On the other hand, SAM generated more output power in February, March, October, and November compared to the GridLAB-D where the differents up tp $25 \%$ to $35 \%$. Meanwhile, months of January, September, and December generated output power almost close to each other where the difference up to $5 \%$. Based on these 


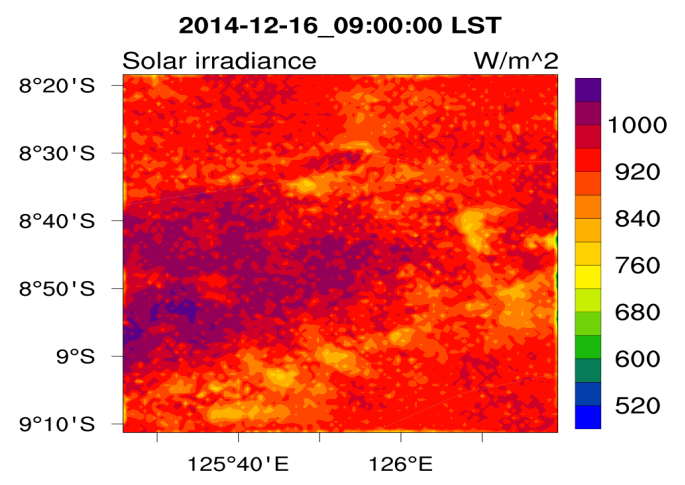

(a)

2014-12-16_15:00:00 LST

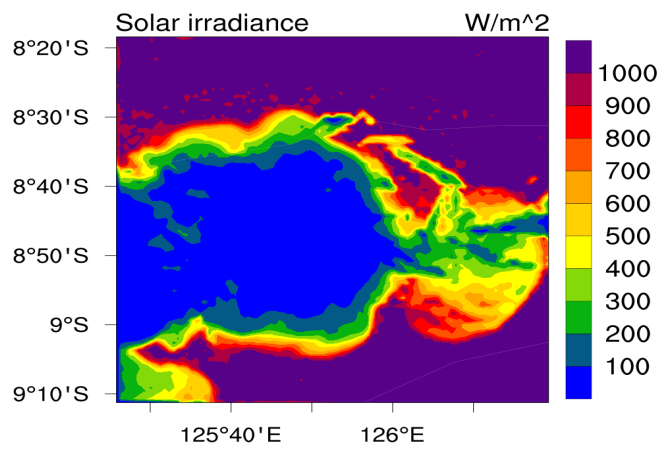

(b)

2014-04-23 09:00:00 LST

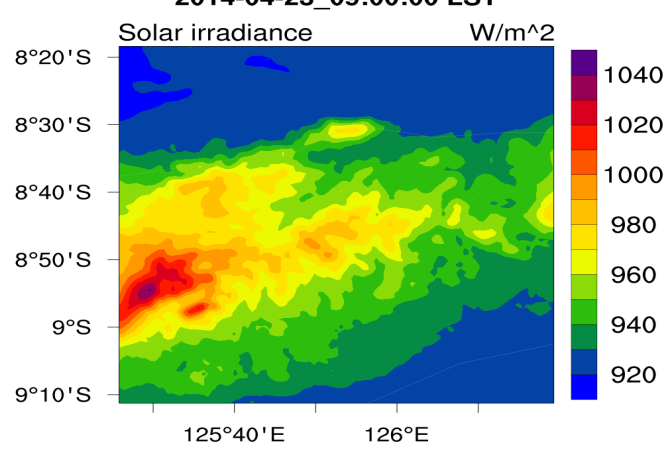

(c)

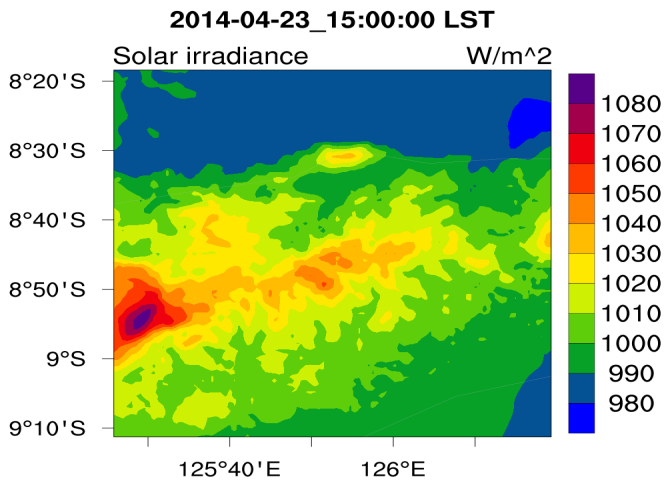

(d)

Figure 5. Plotting of solar irradiance. (a) Sunny day at 09 morning; (b) Sunny day at 03 afternoon; (c) Rainy day at 09 morning; (d) Rainy day at 03 afternoon. 


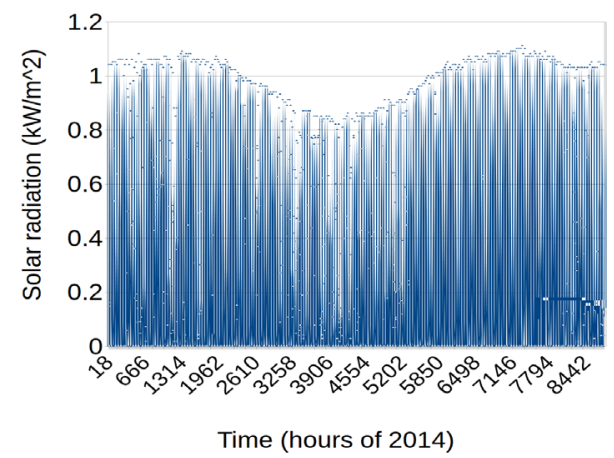

(a)

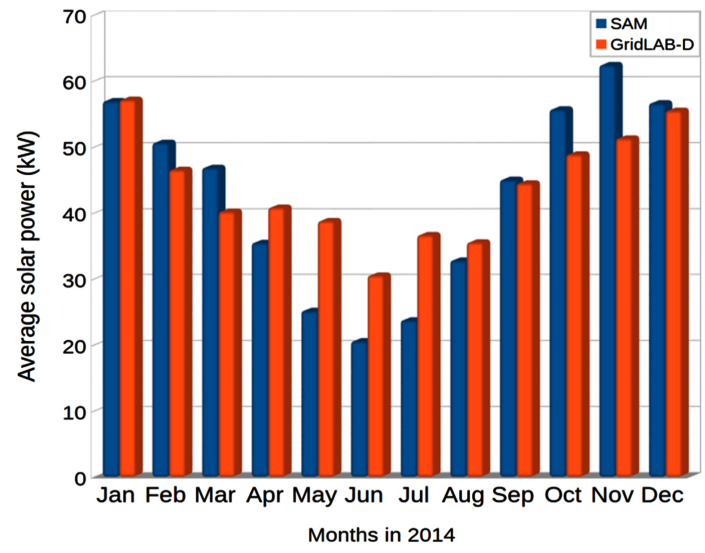

(b)

Figure 6. (a) Plotting of 8760 hours of solar radiation in 2014; (b) Comparison of output average solar power between SAM and GridLAB-D.

solar power output results, the performance of these two methods is dependent on the local time (hour, minutes, and seconds) and universal time (green meridian time (GMT)) because sun movement is determined by the given date falls on a leap year. Apart from solar time parameters, solar altitude, solar azimuth, solar declination, day number, latitude, longitude, altitude, and weather conditions must be determined to perform solar power generation. In addition, the specification or characteristics of solar panels such as rated power, inverter efficiency, power factor, and inverter types may affect the output results of power generations.

In addition, based on the result of solar power from one-year simulated data in 2014, the calculation of output for annual was also done using the SAM model to analyze energy production for 25 years. The estimation result of the annual energy production from the solar PV system for 25 years almost equivalent to $350 \mathrm{MWh}$ which may cause the price of net present value (NPV). As shown in Table 5, the prices of NPV determined by the calculation of the costs and the benefit of an investment of a period for the PV panel system. NPV then will determine whether a project of solar farms is profit (if NPV is obtained in positive value) or loss (if NPV is obtained in a negative value). In this present study, the PV system presents negative values for a year indicating the loss of the project 
Table 5. Analyses output values of solar PV system.

\begin{tabular}{cc}
\hline Metric & Value \\
\hline Annual energy (year 1) & 373,409 \\
Capacity factor (year 1) & $17.1 \%$ \\
Energy yield (year 1) & $1494 \mathrm{kWh} / \mathrm{kW}$ \\
Levelized COE (nominal) & $14.24 \mathrm{\Phi} / \mathrm{kWh}$ \\
Levelized COE (real) & $11.27 \mathrm{\phi} / \mathrm{kWh}$ \\
Electricity bill without system (year 1) & $\$ 826,030$ \\
Electricity bill with system (year 1) & $\$ 787,244$ \\
Net savings with system (year 1) & $\$ 38,785$ \\
Net present value & $\$-101,885$ \\
Payback period & 14.6 years \\
Discounted payback period & NaN \\
Net capital cost & $\$ 531,834$ \\
Equity & $\$ 531,834$ \\
Debt & $\$ 0$ \\
\hline
\end{tabular}

PV system itself. The equity values are equal to the total installed cost for the cash project.

Meanwhile, one of the abilities of the SAM is the calculating of tax cash flow after the project installed. The result shows that annual cash flows are not also constant for a project with a 25-year life as it may also cause by tax-deductible debt interest payments, periodic operating and maintenance $(\mathrm{O} \& \mathrm{M})$ costs and incentive payments in the first 5 years. The year zero value shows a negative number as the initial investment amount. The year one value is the sum of the year one cash flow and the initial investment, year two is the sum of the year one cumulative cash flow and the year two cash flow, etc.

Another ability of the SAM is to calculate the financing of the solar PV system using one calendar year data. Table 5 shows the results of LCOE for both nominal and real costs estimated by NREL SAM including the annual energy generation, capacity factor, payback period, net capital cost, equity cost, and annual energy yield. The results show that the cost of energy of the nominal LCOE and real LCOE is 14.24 cents/kWh and 11.27 cents/kWh, respectively. SAM is also considering the effect of with system or without the system for the electricity bill. SAM applied both systems of the annual electricity system to calculate the annual value of electricity savings.

\section{Conclusions}

In this study, the simulation of the WRF model was conducted in Dili Timor Leste for a full calendar year in 2014, focusing on the simulation of the solar radiation. In addition, the full calendar year performance comparison of two 
methods such as SAM and GridLAB-D for solar power generation was also conducted in Dili Timor Leste. The previous studies regarding wind power generation have done in Dili Timor Leste by the same author. This study continuously from the previous study aims to predict solar power generation based on local solar radiation. The performance of the WRF model to forecast hourly solar radiation is helpful to analyze the solar power generation in itself. The WRF model uses 1 degree $\times 1$ degree of six hourly interval from the NCEP FNL datasets is able to simulate solar radiation for comparison purposes of solar power generation. Since there is a lack of information about solar radiation, pressure, and relative humidity from the weather station observed data in 2014, the five days temperature values from the weather station were used for validation with the temperature at 2-m from the WRF model simulation. Meanwhile, the five days data of solar radiation in year of 2015 from weather station are used to validate in order to understand the performance of the WRF model simulation. However, due to the high computational cost and timing of the runs, it appears not feasible to the author to simulate one more calendar year for solar radiation. Despite inherent limitations in this study, the performance configuration of the WRF model is able to simulate solar radiation well for one-calendar year. Meanwhile, the relative humidity and pressure obtained from the date and time homepage are valuable points to analyze the performance of the temperature from the weather station observed data.

The study of new energy supply sources must be of focus and interest for the governmental institutions. Converting of solar radiation forecasting to power output is a good choice to evaluate the performance of solar forecasting operational. Plotting of solar radiation and solar PV power generation in this study contains very important information that can help and guide for further analysis of solar potentiality of this country, it is because there are still in remote rural areas which do not have access to the energy service. The performance of LCOE will consider the initial investment and operating cost which can be used as a decision criterion for the financial investment.

The consideration of this study is that the implementation of the WRF model as a NWP for solar radiation forecasting and the application of SAM and GridLAB-D for the solar power generation are to recommend highly to the government of Timor Leste as a decision maker in order to focus and pay more attention about solar radiation, it is because Timor Leste is a country with high potency of annually solar radiation for solar farm installation. To conclude this study, the presented methodology such as WRF model, SAM, and GridLAB-D simulator are very useful tools for technologies related to the management of solar source in PV power plants, where forecasting of solar radiation can be applied as decision system for the correct implementation of a technological system based on local atmospheric conditions. Furthermore, the proposed solar radiation forecasting and solar power generation using the WRF model, SAM, and GridLAB-D simulator is suitable and useful to perform for solar farm for tropical countries. Particularly, in the Timor Leste region, implementation and 
improving the management system of the PV power plant as grid-connected or stand-alone electric power projects will be expected to increase the quality of electricity generation for long term period use. For future research, this study will use WRF-Hydro method to predict water production in Dili Timor Leste in order to analyze Hydro-power generation.

\section{Acknowledgements}

The author would like thank to Dr. Ruben Jeronimo Freitas as a lecturer of the Faculty of Engineering for providing the weather station observed data. Special thanks to Dr. Cancio Monteiro as senior lecturer in Hera campus for discussion and advice. The author would like thank the NCEP FNL website and "date and time" website for their free available downloaded data.

\section{Conflicts of Interest}

The author declares no conflicts of interest regarding the publication of this paper.

\section{References}

[1] Timor Leste Strategic Plan 2011-2030. http://timor-leste.gov.tl/wp-content/uploads/2011/07/Timor-Leste-Strategic-Plan-2 011-20301.pdf

[2] Shahsavari, A. and Akbari, M. (2018) Potential of Solar Energy in Developing Countries for Reducing Energy-Related Emissions. Renewable and Sustainable Energy Reviews, 90, 275-291. https://doi.org/10.1016/j.rser.2018.03.065

[3] de Araujo, J.M.S. (2019) WRF Wind Speed Simulation and SAM Wind Energy Estimation: A Case Study in Dili Timor Leste. IEEE Access, 7, 35382-35393.

https://doi.org/10.1109/ACCESS.2019.2904755

[4] Dobos, A., Neises, T. and Wagner, M. (2014) Advances in CSP Simulation Technology in the System Advisor Model. Energy Procedia, 49, 2482-2489. https://doi.org/10.1016/j.egypro.2014.03.263

[5] Broeer, T., Fuller, J., Tuffner, F., Chassin, D. and Djilali, N. (2014) Modeling Framework and Validation of a Smart Grid and Demand Response System for Wind Power Integration. Applied Energy, 113, 199-207. https://doi.org/10.1016/j.apenergy.2013.06.058

[6] Ezeanya, E.K., Massiha, G.H., Simon, W.E., Raush, J.R. and Chambers, T.L. (2018) System Advisor Model (SAM) Simulation Modelling of a Concentrating Solar Thermal Power Plant with Comparison to Actual Performance Data. Cogent Engineering, 5, Article ID: 1524051. https://doi.org/10.1080/23311916.2018.1524051

[7] Hera Town. https://www.tripmondo.com/east-timor/dili/cristorei/hera/

[8] Skamarock, W., Klemp, J., Dudhia, J, Gill, D., Barker, D., Duda, M., et al. (2008) A Description of the Advanced Research WRF Version 3. http://dx.doi.org/10.5065/D68S4MVH

[9] Hong, S.-Y., Dudhia, J. and Chen, S.-H. (2004) A Revised Approach to Ice Microphysical Processes for the Bulk Parameterization of Clouds and Precipitation. Monthly Weather Revision, 132, 103-120. https://doi.org/10.1175/1520-0493(2004)132<0103:ARATIM>2.0.CO;2 
[10] Mlawer, E.J., Taubman, J., Brownn, P.D., Iacono, M.J. and Clough, S.A. (1997) Radiative Transfer for Inhomogeneous Atmospheres: RRTM, a Validated Correlated-k Model for the Longwave. Journal of Geophysical Research: Atmospheres, 10216663 16682. https://doi.org/10.1029/97JD00237

[11] Iacono, M.J., Mlawer, E.J., Clough, S.A. and Morcrette, J.-J. (2000) Impact of an Improved Long Wave Radiation Model, RRTM, on the Energy Budget and Thermodynamic Properties of the NCAR Community Climate Mode, CCM3. Journal of Geophysical Research: Atmospheres, 105, 14873-14890.

https://doi.org/10.1029/2000JD900091

[12] Chen, F. (2007) The Noah Land Surface Model in WRF. https://www.atmos.illinois.edu/ snesbitt/ATMS597R/notes/noahLSM-tutorial.pdf

[13] Hong, S.Y., Noh, Y. and Dudhia, J. (2006) A New Vertical Diffusion Package with an Explicit Treatment of Entrainment Processes. Monthly Weather Review, 134, 2318-2341. https://doi.org/10.1175/MWR3199.1

[14] Bianco, L. Surface Layer Parameterization in WRF. http://cires1.colorado.edu/science/groups/pielke/classes/at7500/Bianco SFC.pdf

[15] NCL (2017) The NCAR Command Language (Version 6.5.0).

[16] Chassin, D.P., Schneide, K. and Gerkensmeyer, C. (2008) GridLAB-D: An Open-Source Power System Modeling and Simulation Environment. IEEE, Chicago, IL, 21-24 April 2008, 1-5. https://doi.org/10.1109/TDC.2008.4517260

[17] System Advisor Model (SAM). https://sam.nrel.gov/

[18] Timor-Leste Ministry of Finance Annual Income-Tax Return. https://www.mof.gov.tl/?s=annual+income\&lang=en

[19] Miller, L., Cariveau, R., Harper, S. and Singh, S. (2017) Evaluating the Link between LCOE and PPA Elements and Structure for Wind Energy. Energy Strategy Reviews, 16, 33-42. https://doi.org/10.1016/j.esr.2017.02.006

[20] Diagne, M., David, M., Boland, J., Schmutz, N. and Lauret, P. (2014) Post-Processing of Solar Irradiance Forecasts from WRF Model at Reunion Island. Solar Energy, 105, 99-108. https://doi.org/10.1016/j.solener.2014.03.016

[21] Olatomiwa, L., Mekhilef, S., Shamshirband, S. and Petković, D. (2015) Adaptive Neuro-Fuzzy Approach for Solar Radiation Prediction in Nigeria. Renewable and Sustainable Energy Reviews, 51, 1784-1792. https://doi.org/10.1016/j.rser.2015.05.068

[22] Khosravi, A., Koury, R.N.N., Machado, L. and Pabon, J.J.G. (2018) Prediction of Hourly Solar Radiation in Abu Musa Island Using Machine Learning Algorithms. Journal of Cleaner Production, 176, 63-75. https://doi.org/10.1016/j.jclepro.2017.12.065

[23] Past Weather in Dili, Timor-Leste. March 2014. https://www.timeanddate.com/weather/timorleste/dili/historic? month=3\&year=2014 


\section{Appendix}

The research article entitled "Performance comparison of solar power generation between GridLAB-D and SAM in Dili, Timor Leste" contains information of Timor Leste region about solar radiation forecasting and solar power generation in the year of 2014. Site of study was conducted in Hera which located about $12.4 \mathrm{~km}$ east of Dili. The 8760 hours data of solar radiation was obtained from WRF model simulation and used as input data to simulate and estimate solar power generation including cost of energy (LCOE). Two methods such as GridLAB-D simulator and System Advisor Model (SAM) are used to simulate generation of solar power. This study uses Intel(R) Core(TM) i7-7700 CPU @3.60 GHz running on Linux Ubuntu 16.0464 bit operating system with 8 GB of RAM. The data of temperature at $2 \mathrm{~m}$ in year 2014 and solar radiation in year of 2015 are used to validate against weather station in Hera.

Value of the data in this study.

- Data available here can be used by other researchers to analyses solar radiation and generation output of solar power.

- Data presented here might be used to understand the performance of simulation and estimation from WRF, SAM, and GridLAB-D about forecasting of solar generation and solar power.

Tables 1-4 of Appendix A.xls. shows data on Hera about output results of solar radiation generated by WRF in year of 2014, average output solar power generation between SAM and GridLAB-D, data validation between WRF and weather station for solar radiation and temperature at $2 \mathrm{~m}$ forecasting in Hera. RADIATION.ncl is computer code used to simulate solar radiation from WRF model.

The below code is used in GridLAB-D to simulate solar power generation in Dili, Timor Leste.

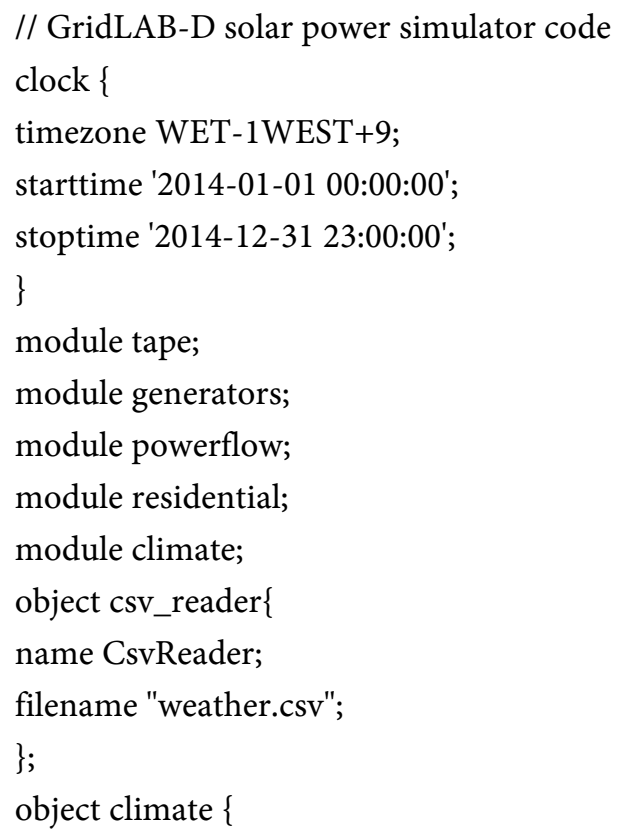




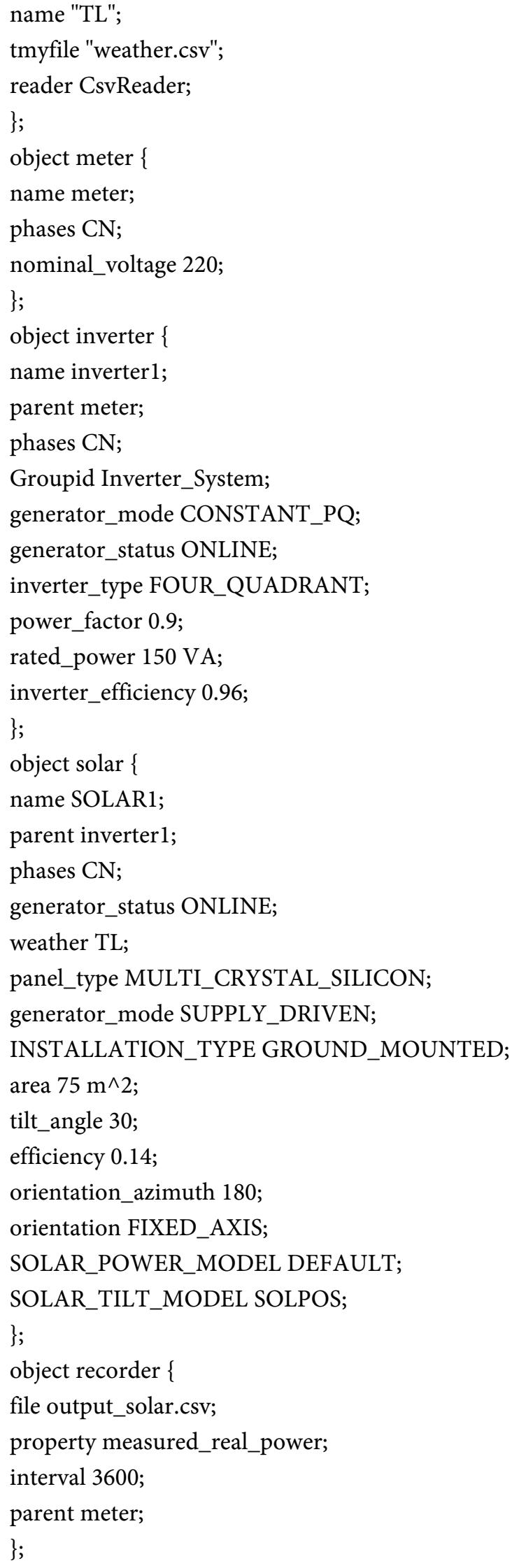

